\title{
CADEIA DE ABASTECIMENTO: GESTÃO DO ESTOQUE PELO DISTRIBUIDOR
}

\section{RESUMO}

Este artigo trata do fluxo de informação e material em uma cadeia de abastecimento de produtos de consumo de quatro níveis. Propõe-se que, pelo menos sob determinadas condições de contorno, os sistemas de gestão nos quais o distribuidor coordena os fluxos de informação e de produtos acabados na cadeia (aqui denominados Estoque Gerido pelo Distribuidor - EGD ou DMI) têm vantagem em comparação com o conceito tradicional de Estoque Gerido pelo Fabricante (EGF ou VMI). Além da avaliação da proposta nas dimensões estratégica e econômica, um modelo de simulação numérica é construído para o estudo do comportamento dinâmico da cadeia. Demonstrou-se que o modelo DMI proporciona posicionamento estratégico e econômico mais sólido ao distribuidor, nas condições analisadas. A análise dinâmica revelou que o modelo é estável, e a simulação permitiu à cadeia específica estudada enfrentar incrementos de $20 \%$ da demanda normal com estoques $55 \%$ menores no varejo e 33\% menores no distribuidor que o modelo VMI de referência.

\section{Joseph Youssif Saab Junior \\ EEM-IMT}

\section{Henrique Luiz Corrêa}

Crummer

\begin{abstract}
This paper deals with the flow of information and material throughout a four-level fast moving consumer goods (FMCG) supplychain. We propose that, under certain circumstances, the coordination of information and material flows along the supply chain should be done by the distributor, in an arrangement called Distributor-Managed Inventory (DMI), a significant departure from the more traditional concept of Vendor-Managed Inventory (VMI) model, in which the aforementioned coordination is done by the manufacturer. We analyze the DMI from both the strategic and the economic perspectives and we also analyze its dynamic behavior by using a numerical simulation model which was built for this specific purpose. We demonstrate that the DMI model has advantages over VMI for the management of this four-level supply chain. Our dynamic analysis simulation, for instance, revealed that the DMI model is stable and allowed the studied chain to face increments of $20 \%$ of the normal demand level with 55\% less inventory at the retail level and 33\% less inventory at the distributor level than a reference VMI model.
\end{abstract}

PALAVRAS-CHAVE Cadeia de abastecimento, varejo, estoque gerido pelo distribuidor, análise dinâmica de sistemas, redução de estoques.

KEYWORDS Supply chain management, retail, distributor-managed inventory, systems dynamics, inventory reduction. 


\section{INTRODUÇÃO}

O objetivo básico da integração das cadeias de abastecimento é o atendimento pleno à demanda, sem falta nem sobra de produtos, o que normalmente inclui um bom nível de previsibilidade e a minimização das flutuações que caracterizam o seu comportamento dinâmico (LEE; PADMANABHAN; WHANG, 1997).

As políticas conhecidas por Troca Eletrônica de Dados (EDI), Resposta Eficiente ao Consumidor (ECR) e Estoque Gerido pelo Fabricante (VMI) são exemplos de iniciativas específicas de integração que visam amenizar tais flutuações e fazem parte da tendência geral em direção aos movimentos de lean-manufacturing e just-in-time (STERMAN, 2000).

No presente estudo fixou-se particular atenção sobre a política do VMI, que atribui ao fabricante a tarefa de gerenciar o nó imediatamente a jusante da cadeia de abastecimento, determinando quando e quanto de cada produto deve ser enviado ao seu cliente imediato. O VMI, portanto, é um sistema no qual o cliente do fabricante abre mão do controle do seu próprio inventário, implicando que esse elo da cadeia precisa operar sob estreita colaboração e confiança (CORRÊA; CORRÊA, 2006).

Apesar do apelo que essa forma de integração possui para o fabricante, constata-se, por meio da literatura da área, que o funcionamento do VMI tem sido, no mínimo, controverso:

Quase um ano após a sua implantação, uma das iniciativas de ECR mais promissoras e arrojadas foi finalizada: a cadeia de lojas Spartan anunciou o desligamento do projeto que seus executivos descreveram como VMI. (RYAN, 1995, p. 64).

Oficialmente, a sigla VMI refere-se ao Estoque Gerido pelo Fabricante (Vendor Managed Inventory). No entanto, cerca de 15 anos após sua introdução, as iniciais poderiam também significar "Impacto Muito Variado" (Very Mixed Impact). Apesar de algumas empresas estarem implementando a prática do VMI, outras estão abandonando o conceito. (COOKE, 1998, p. 51).

Muitos relatos publicados têm descrito os benefícios do VMI, que vão desde lançamentos mais econômicos de produtos até menores trocas por vencimento de prazo, mas a literatura freqüentemente não explica por que esses benefícios resultam do VMI. Da mesma forma que ocorre com outras teorias gerenciais, é difícil distinguir resultados reais do exagero, assim como é difícil determinar como esses resultados poderiam ser reproduzidos em outras situações. (WALLER et al., 1999, p. 183).
Por meio da compreensão e do gerenciamento de custos, e do controle do risco mediante negociações cuidadosas, pode-se fazer tanto o VMI como a consignação trabalharem não apenas para o cliente, mas também para o fornecedor. (WILLIAMS, 2000, p. 63).

Além da literatura, a observação do esforço frustrado de implantação de um sistema tipo VMI, no estado de São Paulo, por iniciativa de um fabricante multinacional de produtos de consumo, suscitou nos autores o desejo de (i) pesquisar mais profundamente a natureza das interações das cadeias de abastecimento em geral e da cadeia analisada em particular, e (ii) propor um modelo de integração que apresentasse maiores chances de êxito na consecução dos seus objetivos.

$\mathrm{Na}$ etapa inicial de investigação (i), dedicada à compreensão da dinâmica das cadeias e teste de aplicabilidade de modelos de integração disponíveis, concluiu-se que nenhum sistema genérico deve ser aplicado a uma cadeia específica sem adaptações para acomodar as particularidades de seus fluxos de material e informação, sob forte risco de insucesso na operação (SAAB; CORRÊA, 2005). No caso da cadeia particular considerada, de acordo com nossas análises, um dos prováveis motivos identificados para o insucesso da iniciativa, acompanhada ao longo de três anos, foi a tentativa de adaptação de um sistema de integração oriundo da cadeia de três níveis (fabricantevarejista-consumidor) a uma cadeia de quatro níveis (fabricante-distribuidor-varejista-consumidor). Isso forçou o fabricante a abdicar das informações provenientes do ponto-de-venda (varejo), concentrando-se apenas nas informações consolidadas e atrasadas de demanda disponíveis em seu cliente imediato (distribuidor).

A busca de alternativas mais promissoras, que constitui a fase (ii) da investigação, resultou na proposta apresentada neste artigo, que trata da análise de viabilidade, sob várias ópticas, da coordenação do fluxo de informação e materiais ser realizada pelo distribuidor em substituição ao fabricante, já que sua posição mais central na cadeia de abastecimento de quatro níveis permitiria maior facilidade na integração das informações provenientes do varejo.

\section{CONCEITOS TEÓRICOS E CARACTERÍSTICAS DO MERCADO CONSIDERADO}

O termo "distribuidor" refere-se, neste artigo, à segunda entidade do sistema de quatro níveis, localizada entre o fabricante e os varejistas, dentro de uma cadeia de abas- 
tecimento de produtos de consumo não durável, e que opera sob o sistema de distribuição exclusiva (LAMBIN, 2000).

Os entes intermediários dos canais - agentes, distribuidores, atacadistas e varejistas - realizam inúmeras atividades envolvidas nos processos de trocas livres e competitivas, objetivando uma ligação eficaz entre os extremos de produção e consumo (ROSENBLOOM, 2002). Tipicamente, eles se associam a fabricantes de produtos diversos formando o complexo agrupamento de instituições por meio do qual um sistema de livre mercado realiza a transferência de propriedade de produtos e serviços (BOWERSOX; CLOSS, 2001).

As cadeias de abastecimento podem ser diretas (do fabricante ao consumidor) ou possuir vários níveis intermediários. Souza (2002) afirma haver duas vertentes para justificar a decisão de integrar ou terceirizar um arranjo de canal de marketing: a teoria do agente e a economia dos custos de transação. A economia proporcionada pela incorporação de intermediários especializados no canal é potencialmente grande e está ilustrada no exemplo numérico da Tabela 1.

\section{A administração da cadeia de abastecimento}

Melhorar a eficiência de uma cadeia é melhorar a eficiência de seus nós (ambiente interno das empresas) e de seus elos (interfaces entre duas empresas consecutivas na cadeia). Após os movimentos intensos de reorganização interna que caracterizaram os anos 1980 e 1990, os "retornos decrescentes" dos esforços de reorganização interna levaram as corporações a voltarem-se para o ambiente externo:
Os 90 anos de desenvolvimento de técnicas de gestão de operações voltadas a melhorias de desempenho dentro dos nós das redes de suprimentos fizeram com que os custos marginais das melhorias incrementais de desempenho dentro dos nós atingissem patamares bastante elevados, devido ao efeito da "lei dos retornos decrescentes". (CORRÊA, 2003, p. 118).

Na cadeia, o fluxo principal de produtos, predominantemente unidirecional, demanda fluxos simultâneos de coordenação, tais como pedidos, pagamentos e principalmente informações (LAMBIN, 2000).

A administração da cadeia de suprimentos visa primariamente oferecer valor adequado ao consumidor e o máximo retorno sobre ativos para os seus participantes por meio da gestão efetiva do fluxo de materiais, informações e recursos financeiros (REIS, 2003). O Retorno sobre Ativos (ROA), para qualquer nó da cadeia, resulta do produto entre Margem Líquida e Giro dos Estoques (WALSH, 1996). No caso do distribuidor exclusivo da cadeia de quatro níveis que atua com produtos de consumo em um mercado competitivo, a sua Margem Bruta é estabelecida de forma exógena, na medida em que o seu Custo da Mercadoria Vendida é, em grande parte, imposto pelo grande poder de barganha do fabricante e o seu Preço de Venda é determinado pelas condições de concorrência do mercado. O distribuidor, portanto, necessita operar bem sobre seus Custos Fixos, e o seu Giro de Estoques, sobre os quais pode exercer maior nível de influência.

Como o Giro de Estoques é avaliado pela razão entre o fluxo de produtos (Custo da Mercadoria Vendida) e o

Tabela 1 - Exemplo de redução no número de transações - avaliação numérica ilustrativa, usando número de componentes representativo em cada nível da cadeia de produtos de consumo analisada

\section{CADEIA DIRETA}

Número de fabricantes $(n)$ :

Número de pontos de varejo $(p)$ :

Número de transações diretas $(n \times p)$ :

CADEIA INDIRETA

Número de fabricantes $(\mathrm{n})$ :

Número de pontos de varejo $(p)$ :

Número de distribuidores:

Número de transações indiretas $(n+p)$ :

ECONOMIA TRANSACIONAL
3

1.000

3.000

\section{3}

1.000

1

1.003

Redução no número de transações $(n \times p)-(n+p)$ :

1.997 
Estoque Médio (também valorado a custo), existe sobre o distribuidor uma grande pressão econômica para a redução do seu Estoque Médio. No entanto, o diagrama de causa e efeito representado na Figura 1, sugere que um eventual esforço direto para reduzir estoques pode, na verdade, piorar o problema ao longo do tempo; isso sugere que a redução de estoques pode ser mais eficaz se ocorrer como uma conseqüência da atuação sobre outros aspectos de gestão que possam resultar em desempenho melhor e mais duradouro (ou, em outras palavras, sobre "pontos de maior alavancagem"). Para auxiliar na identificação genérica de pontos de maior alavancagem, pode-se recorrer, por exemplo, à pesquisa de Kirkwood (1998), que mostra que modificar os elos de informação em um processo de negócios (por exemplo, com maior nível de compartilhamento de informações entre os "nós") pode ter impactos profundos no seu desempenho. Isso sugere que a solução para maior eficiência do fluxo de material pode estar na forma como se realiza e coordena o fluxo de informação na cadeia de abastecimento.

No entanto, o compartilhamento de informações entre nós de uma cadeia pressupõe a existência de vínculos de confiança entre os entes, algo que não ocorre em grande número de cadeias, inclusive na cadeia investigada pelos autores. A situação em que uma das partes domina o relacionamento (POIRIER; REITER, 1997) pouco favorece o surgimento de confiança entre os seus elementos, pré-requisito para o estabelecimento do fluxo bidirecional de informação que permite gerar valor por meio da integração.
Uma cadeia de abastecimento deve ter um elemento que una os membros, do contrário a rede terá pouca substância. Em uma situação típica esse elemento é a influência da posição. [...] Os membros mais poderosos simplesmente exercem sua força sobre os participantes mais fracos [...], e extraem concessões injustificadas para garantir a continuidade do fornecimento [...]. (POIRIER; REITER, 1997, p. 95).

\section{Elementos de análise dinâmica}

As propostas de coordenação e integração são tradicionalmente justificadas pelas análises estratégicas e financeiras. No entanto, ao se agruparem diversas empresas na forma de uma cadeia de abastecimento, os atrasos nos fluxos de informação e materiais (produtos) dão origem a um fenômeno dinâmico marcante, na forma de oscilações, que influi diretamente na sua economia. Do estudo de Forrester (1973) surgiu uma melhor compreensão dessas oscilações nos fluxos de capital, pedidos, informações, materiais, pessoas e bens, que se estabelecem ao longo dos elos de uma cadeia de abastecimento. Em sua homenagem, denominase "efeito Forrester" (LEE; PADMANABHAN; WHANG, 1997) ao comportamento caracterizado pelo aumento de variância da demanda nos níveis da rede a montante do ponto de consumo quando uma perturbação qualquer é introduzida na cadência normal de vendas do varejo.

Forrester (1973) utilizou, de forma original, uma estrutura de produção-distribuição de bens de consumo duráveis (eletrodomésticos) para demonstrar numericamente como a forma e as políticas organizacionais podem origi-

Figura 1 - A pressão direta para a redução do excesso de estoque é auto-reforçadora

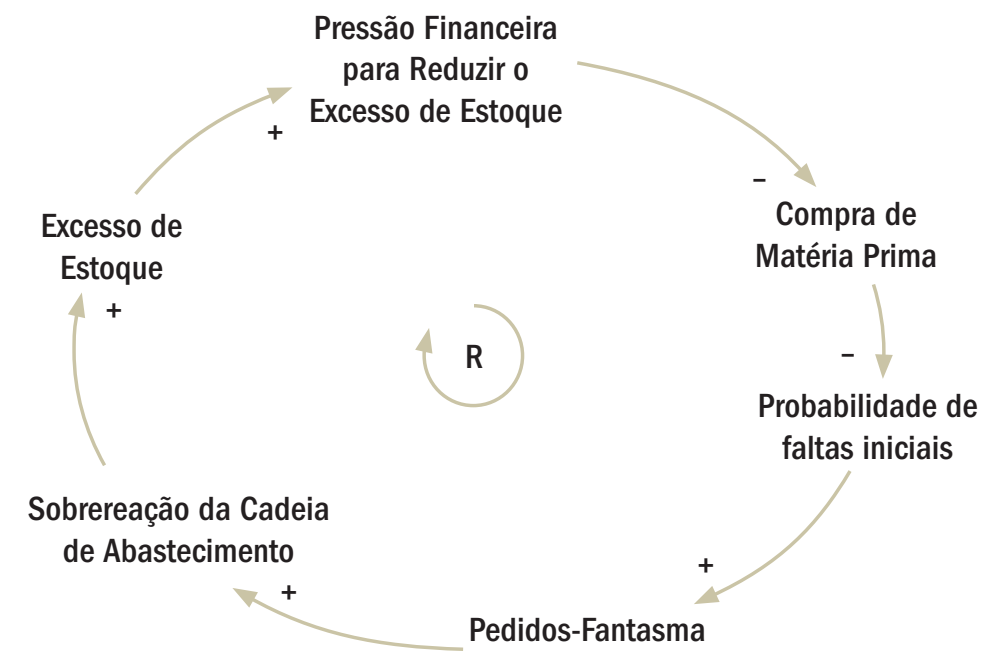

Fonte: STERMAN, 2000. 
nar comportamentos característicos indesejáveis. Como exemplos, pequenas mudanças nas vendas do varejo podem ensejar grandes flutuações na produção da fábrica; a redução dos tempos envolvidos em atrasos administrativos pode ser insuficiente para melhorar as condições das decisões gerenciais; uma fábrica pode ficar impossibilitada de atender pedidos mesmo quando é capaz de produzir mais bens do que estão sendo vendidos aos consumidores; ou ainda, uma campanha publicitária pode amplificar a variância na demanda do nó de produção de forma totalmente imprevista.

Existe, portanto, uma sistemática desenvolvida que permite testar o resultado dinâmico de propostas de coordenação, e isso deveria ser um critério discriminante na avaliação de qualquer proposta de integração para uma cadeia de abastecimento.

Dentre suas diversas conclusões e propostas, Forrester (1973) demonstrou que as oscilações típicas da cadeia poderiam ser reduzidas por meio da diminuição do número de níveis intermediários (distribuidores e varejistas). Não obstante, decorridos mais de 30 anos da publicação original de seu trabalho, outros autores (ROSENBLOOM, 2002) continuam a atribuir aos distribuidores uma função importante na cadeia de distribuição globalizada, em parte devido à economia dos custos de transação ilustrada anteriormente na Tabela 01.

Uma segunda e mais recente onda de propostas de "desintermediação" de cadeias surgiu com o avanço da Internet, que possibilitou o aumento de interação direta entre os elementos extremos da cadeia de abastecimento (fabricante e consumidor). No entanto, apesar das intensas mudanças, a crença de que a Web eliminaria os intermediários dos vários processos de negócios acabou sendo considerada um dos mitos da Internet, segundo Albertin (2001). De acordo com o mesmo autor, "[....] a desintermediação que já ocorreu e ainda ocorrerá está relacionada com os elos da cadeia que não agregam valor e simplesmente unem as duas pontas" (ALBERTIN, 2001, p. 93).

O principal legado de Forrester (1973) é a metodologia para aplicação da Análise Dinâmica de Sistemas ao mundo dos negócios. Essa metodologia completa o chamado "pensamento sistêmico", que "é um quadro de referência conceitual, um conjunto de conhecimentos e ferramentas desenvolvido ao longo dos últimos cinqüenta anos para esclarecer os padrões como um todo e ajudar-nos a ver como modificá-los eficazmente" (SENGE, 2002, p. 40).

Na prática do pensamento sistêmico é possível representar qualquer processo de negócio por meio de uma notação chamada "diagrama de estoque e fluxo", durante as etapas de definição do problema e delimitação de suas fronteiras (KIRKWOOD, 1998). Nesse tipo de diagrama, estoques, fluxos e informações relevantes representam as relações entre as partes de um sistema. Não são relevantes informações detalhadas, tais como os equipamentos empregados, mas sim as características compartilhadas pelos processos de negócio e seus componentes. Todos esses processos podem ser caracterizados em termos de variáveis de apenas dois tipos: estoques (níveis e acúmulos) e fluxos (taxas). De acordo com Kirkwood (1998), décadas de trabalhos práticos confirmam que essa abordagem pode resultar em vantagem competitiva.

\section{A evolução da cadeia de abastecimento de produtos de consumo no Brasil}

Com a estabilização da inflação brasileira alcançada com o conjunto de medidas adotadas por ocasião do Plano Real, em 1994, iniciou-se gradativamente uma mudança nos hábitos de consumo da população dos grandes centros, e o pequeno varejo independente brasileiro, gradativamente, tornou-se o canal mais importante na distribuição de bens de consumo no país, escoando mais da metade da produção nacional e alcançando crescimento real de 11\% em 2002 e 5,8\% em 2003, de acordo com a Associação Brasileira dos Atacadistas e Distribuidores (ABAD, 2003). Os fabricantes chegam de forma direta a somente $5 \%$ dos pontos-de-venda do território nacional. Dependem, portanto, da cadeia composta para atingir todo o restante, o que demonstra a importância dessa atividade para a vascularização do consumo brasileiro (BAUMGARTEN, 2006).

O pequeno varejista, tradicionalmente atendido de forma intermitente por meio de longas e descoordenadas cadeias de abastecimento, passou a representar um novo alvo estratégico, que permitiria aos fabricantes reduzir a influência e o poder de barganha das grandes redes de varejo, que passaram a consolidar-se a partir dos anos 90 (PARENTE, 2000). Visando aproveitar essa oportunidade, alguns fabricantes de bens de consumo estabelecidos no Brasil começaram a redesenhar seus sistemas de distribuição (SAAB, 2003), reelegendo o canal de distribuição de quatro níveis como um dos destinos prioritários para investimentos e ampliação de vendas.

Com o crescimento da importância estratégica dos canais mais longos, os fabricantes tentaram adaptar a esse novo segmento as ferramentas de coordenação existentes (como, por exemplo, o VMI), que haviam sido desenvolvidas, a um grande custo organizacional e financeiro, para o gerenciamento da interface com as grandes redes varejistas (protagonistas de canais mais curtos de distribuição). 
O resultado dessa iniciativa de adaptação do VMI a canais mais longos não atendeu as expectativas de redução de oscilações de demanda nos vários níveis da cadeia de suprimentos analisada, tendo se mantido largamente inalterados os perfis de oscilação, mesmo após o intervalo observado de três anos decorridos da implantação da iniciativa.

\section{A proposta de um sistema alternativo ao VMI}

Do ponto de vista da análise dinâmica de sistemas, segregar o nível do varejo representa uma importante desconsideração no desenho de qualquer sistema de informação que vise uma integração mais completa da cadeia de abastecimento, já que fica excluída a possibilidade de medirse a demanda no ponto onde as suas variações podem ser detectadas mais cedo. As flutuações de demanda não tratadas na fonte amplificam-se e tornam-se mais difíceis de neutralizar a montante da cadeia de abastecimento em decorrência do "efeito Forrester" (para detalhes, veja, por exemplo, LEE; PADMANABHAN; WHANG, 1997).

Além dessa evidente limitação, Saab e Corrêa (2005) demonstram que a transposição de um sistema de coordenação de informação entre cadeias de abastecimento exige a identificação e o ajuste dos novos pontos de alavancagem para uma correta operação no novo ambiente. Isso ajuda a explicar e reforça a afirmação de SIMBARI (1996, p. 94), de que:

\section{[....] essas iniciativas da indústria - ECR, VMI, CRP e QR - falharam em resolver totalmente as necessidades das com- panhias que produzem e distribuem produtos porque as iniciativas não foram desenvolvidas especificamente para indústrias particulares. Essas técnicas não coordenam o processo de oferta-demanda, que é o principal ponto onde os fabricantes e os distribuidores precisam coordenar ne- cessidades e reabastecimentos. Além disso, os processos não acomodam parceiros comerciais diferentes que usam outros sistemas ou práticas convencionais.}

Torna-se evidente, portanto, que a integração bem-sucedida da cadeia de quatro níveis dependeria da adoção de soluções mais amplas em alguns aspectos (integrando, por exemplo, todos os nós envolvidos) e mais específicas em outros, para atender as particularidades da cadeia em questão.

O projeto de estender o gerenciamento do fluxo de informações para toda a cadeia de quatro níveis poderia, em tese, ser coordenado por qualquer uma das entidades que a constituem, exceto o consumidor. Não obstante, uma análise preliminar dos nós da cadeia nos sugeriu que o distribuidor poderia ser um candidato mais apropriado para realizar a coordenação de informações entre os demais entes (ou nós da rede) envolvidos.

A primeira e mais forte evidência nesse sentido decorre do fato de que tanto o fabricante típico de produtos de consumo como os pontos de varejo fazem parte de dezenas ou até centenas de cadeias de abastecimento distintas, necessárias para entregar produtos de centenas de fabricantes em toda a extensão territorial de grandes países como o Brasil, num arranjo complexo, às vezes denominado rede de suprimentos (ou supply network, na literatura de língua inglesa). Em contraste, o distribuidor é o ente que participa do menor número de cadeias, e, se for um distribuidor exclusivo, como o caso aqui considerado, participa de uma única cadeia de abastecimento a montante da sua posição.

Considerando as necessidades de particularização do sistema de informação a cada cadeia específica (devidas, às vezes, a particularidades dos diferentes modelos de negócios envolvidos e, às vezes, a incompatibilidades entre os sistemas de informação de diferentes entes envolvidos), o fabricante e o varejista teriam, na prática, mais dificuldade de estabelecer um modelo único de coordenação, pois participam de numerosas cadeias, enquanto o distribuidor exclusivo, atuando em apenas uma, estaria em posição privilegiada para fazê-lo.

Além dessa limitação de ordem prática, o fabricante tem responsabilidades e competências primariamente relacionadas à pesquisa, ao desenvolvimento e à fabricação e, em alguns casos, às atividades de promoção dos seus produtos, enquanto ao varejo cabe realizar a cada vez mais importante atividade de prestação de serviços ao consumidor, com o objetivo de conformar um "pacote de valor" diferenciador dos produtos oferecidos, crescentemente comoditizados (CORRÊA et al., 2007). Por outro lado, como a atividade preponderante do distribuidor é prestar serviços de distribuição para a cadeia em que se encontra, esse nó da cadeia nos pareceu ter uma posição privilegiada para exercer a coordenação de fluxos, tanto materiais como de informação, já que essa coordenação é aparentemente bastante próxima de suas atividades mais centrais.

Com base na argumentação construída a partir das análises preliminares do caso estudado, o objetivo da pesquisa aqui relatada foi definido como a exploração e análise de um modelo alternativo de gestão de cadeias de abastecimento de quatro níveis, no qual o distribuidor (e não o fabricante, como ocorre nos mais tradicionais modelos de VMI) exerce o papel de "coordenador" dos fluxos de informação e de materiais ao longo da cadeia. De forma 
sintética, dentro do novo modelo proposto, denominado de Estoque Gerido pelo Distribuidor (EGD ou DistributorManaged Inventory, DMI), o distribuidor passa a (i) ter acesso direto, com alta freqüência, aos dados de demanda dos produtos por ele fornecidos ao varejo; (ii) transferir dados de demanda do varejo ao fabricante, também com alta freqüência, para melhor dimensionamento da produção; (iii) calcular as quantidades de reposição necessárias nos pontos-de-venda de forma a manter o nível de serviço e giro elevado de estoques, além de garantir o nível de estoque de segurança acordado com cada varejista; e (iv) considerar tendências macro-regionais, como sazonalidade, e micro-regionais, identificadas pelos dados de venda dos demais clientes da mesma micro-região, na determinação das quantidades e tipos de produtos mais apropriados para cada loja de varejo. Esse sistema de coordenação pressupõe a existência de uma infra-estrutura apropriada de tecnologia de informação, hoje crescentemente possível e viável, dadas as novas tecnologias de interconectividade entre empresas.

\section{METODOLOGIA}

O procedimento metodológico adotado foi submeter à análise, sob diversos aspectos, o modelo de coordenação de informações proposto para a cadeia de abastecimento de quatro níveis. O primeiro desafio enfrentado foi quanto à determinação de um modelo para avaliar a proposta.

Modelos tradicionais de avaliação de investimentos e projetos envolvem estimativas do investimento, do fluxo de caixa gerado ao longo da vida útil e da taxa de desconto do capital a ser aplicada na estimativa do valor presente líquido, considerando basicamente os valores tangíveis na análise. Outras propostas mais modernas (KAPLAN, 1986; SAMUELS et al., 1990; BROMWICH; BHIMANI, 1991) procuram quantificar os valores intangíveis para incluí-los nas decisões ou ainda garantir que o projeto esteja alinhado com a estratégia geral da empresa antes, até, da avaliação financeira. Não obstante, nenhum modelo apropriado de avaliação para projetos na cadeia de abastecimento foi encontrado na literatura pesquisada, uma vez que nenhum deles se ocupa do impacto que as suas respostas dinâmicas trariam às dimensões econômicas e financeiras. Além disso, a resposta dinâmica é importante como uma dimensão autônoma, já que qualquer novo arranjo proposto deve conduzir à estabilidade, ou seja, deve levar à redução da amplitude e freqüência das oscilações de sua demanda, em qualquer de seus nós.
Propôs-se um novo modelo para avaliação das decisões na cadeia de abastecimento. Inicialmente, verifica-se se a transformação está alinhada à estratégia da empresa e do canal. Em seguida, a transformação é testada em uma simulação dinâmica de comportamento da cadeia, e finalmente, a proposta é analisada sob o aspecto econômico-financeiro, utilizando-se as métricas de Margem de Contribuição e Giro dos Estoques, escolhidas por influírem diretamente no resultado operacional de todos os entes da cadeia e por permitirem mais fácil generalização do resultado, uma vez que independem da estrutura de custos fixos de qualquer empresa em particular. Esses parâmetros não foram estimados com base em projeções lineares comuns, mas obtidos diretamente das simulações dinâmicas realizadas.

Para a avaliação estratégica, empregou-se a tradicional análise das pressões competitivas de Porter (1999) adaptada para o estudo das pressões competitivas existentes na interface entre distribuidor e mercado. Além disso, considerou-se também a visão baseada em recursos, com o uso do conceito de "competências centrais" (HAMEL; PRAHALAD, 1994).

Tanto para a análise estratégica como para a econômica, recorreu-se ao estudo de um caso particular como referência. A cadeia analisada é parte de uma rede de abastecimento que envolve um fabricante multinacional de produtos de consumo não durável estabelecido há muitas décadas no Brasil, um dos seus distribuidores exclusivos no estado de São Paulo e os varejistas servidos por esse distribuidor. Em uma reestruturação de seus canais de distribuição, realizada pelo fabricante em 2001, os distribuidores foram apontados como parceiros estratégicos na consecução dos objetivos de longo prazo, e com isso fora iniciado um projeto de conectividade, visando a implantação do Estoque Gerido pelo Fabricante (VMI). Os autores tiveram a oportunidade de acompanhar de perto tal transformação, além de terem tido acesso livre a grande quantidade de dados da cadeia.

Para a análise dinâmica, montou-se um modelo matemático da cadeia de quatro níveis, que foi aferido e submetido a simulações. A montagem do modelo seguiu a metodologia usual em análise dinâmica de sistemas, com a preparação prévia de um diagrama de relação causal e de um diagrama de estoque e fluxo, reproduzido na Figura 2.

Para a simulação numérica, todas as interações entre os entes da cadeia previstas no diagrama de estoque e fluxo (Figura 2), fossem eles conservativos (estoques) ou não conservativos (informações), foram transformadas em equações, depois numericamente integradas ao longo de 
um intervalo de tempo escolhido. Com base nos valores iniciais de cada variável, e nas iterações numéricas, foi possível conhecer os valores intermediários e finais de todas as variáveis de interesse para avaliação do modelo. Para realizar a operação, recorreu-se ao software VenSim ${ }^{\circledR}$, que, além de auxiliar na organização dos diagramas necessários, utiliza o método de Euler (KOPCHENOVA; MARON, 1975) para integrar numericamente as equações resultantes do modelo. Tomaram-se os cuidados específicos para garantir a estabilidade do método durante a integração, como, por exemplo, a escolha apropriada do passo temporal frente às constantes de tempo presentes no modelo. O modelo final usado no teste foi o décimo sétimo na seqüência de estudos e apresentou pleno fechamento matemático, isto é, igualdade entre número de incógnitas e equações, além de homogeneidade nas unidades dos estoques e fluxos.

Uma das principais características do modelo desenvolvido foi a sua flexibilidade, que permitiu testar e comparar as diferentes políticas de administração da cadeia de abastecimento representadas pelo tradicional VMI e pelo DMI proposto neste trabalho. Para tanto, bastou que se alterasse a freqüência com que as informações eram trocadas entre os nós da cadeia. Por exemplo, no caso do VMI, o fluxo de informações das vendas do varejo chegava ao fabricante apenas indiretamente (por meio das vendas do distribuidor), e com baixa frequêencia, o que foi deno- minado acoplamento "frouxo" da cadeia. Para simular o DMI, as informações de vendas do varejo chegavam não apenas de forma direta ao distribuidor, como também com elevada freqüência, o que foi denominado acoplamento "rígido" da cadeia.

O intervalo de tempo selecionado para a simulação foi de 50 semanas, ao longo das quais se estudaram as respostas dinâmicas da cadeia para as situações de acoplamento frouxo e rígido. Como foram feitas diversas simulações preliminares, o critério escolhido para os estoques iniciais em todos os elos era o mínimo valor necessário para não haver faltas durante o período de simulação. O estímulo que permitia avaliar a estabilidade e adequação de cada modelo ocorria invariavelmente na décima semana de cada simulação, na forma de um aumento instantâneo de $20 \%$ na demanda do consumidor (função degrau ou step function). Apesar de não representar uma situação freqüente de mercado, um choque instantâneo de consumo dispara todas as freqüências de resposta possíveis em um modelo dinâmico (KIRKWOOD, 1998), testando profundamente o mesmo quanto à sua robustez. As dez semanas iniciais de simulação tinham a importante tarefa de comprovar que o sistema encontrava-se totalmente em equilíbrio antes do choque, o que permitia atribuir a ele toda a resposta dinâmica que se seguiria àquele instante, ao longo da simulação numérica.

Figura 2 - Diagrama de estoque e fluxo do modelo EGD-DMI proposto para a cadeia de abastecimento particular analisada

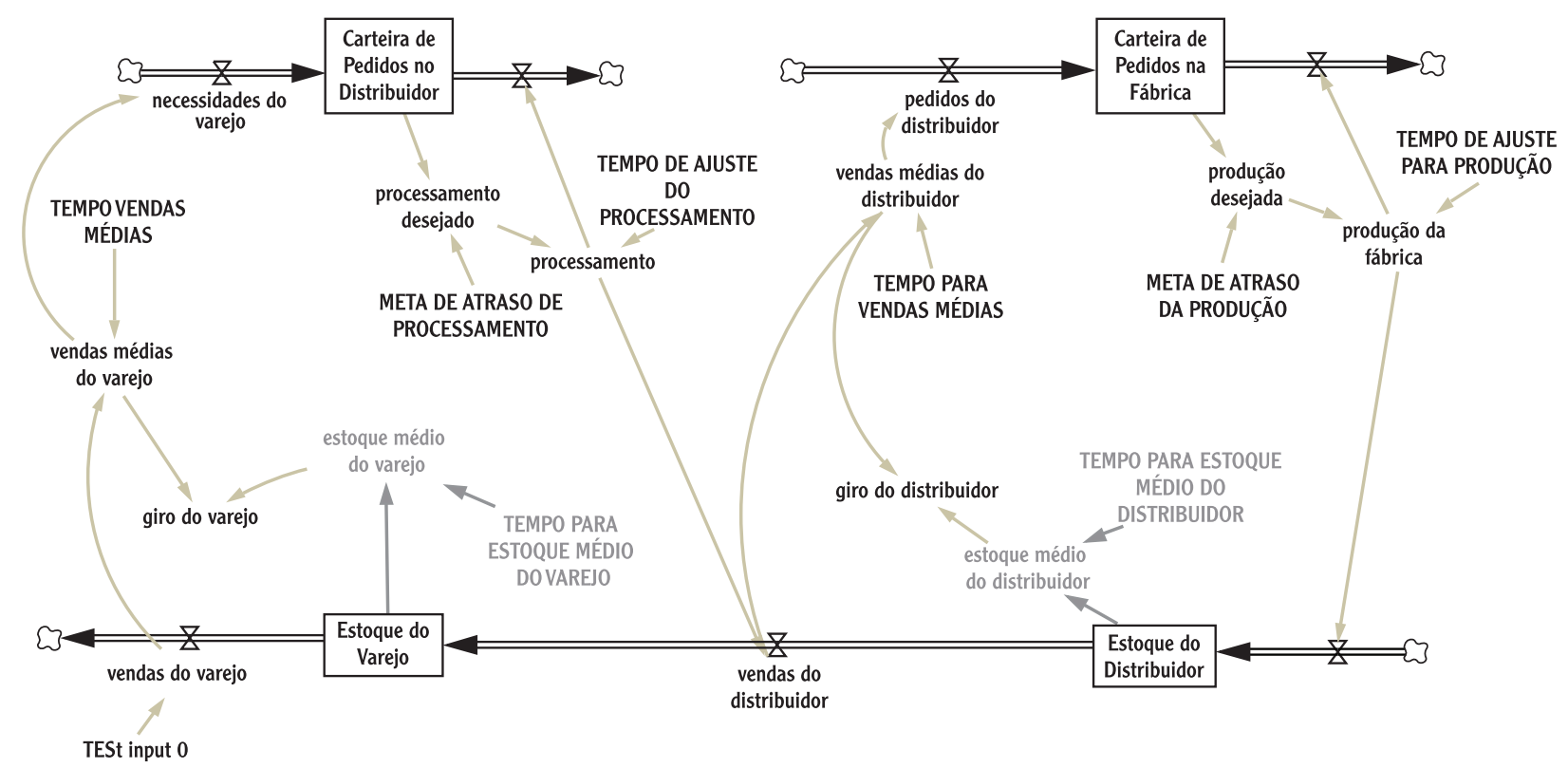




\section{ANÁLISE DOS DADOS E RESULTADOS}

\section{Análise estratégica}

Quatro das cinco "forças competitivas" de Porter (1999) são particularmente relevantes para a presente análise estratégica: o "poder de barganha dos fornecedores", a "ameaça de concorrentes", a "ameaça de novos entrantes" no mercado e o "poder de barganha dos clientes".

Considerações sobre o poder de barganha dos fornecedores: Com relação ao fornecedor (fabricante), os aspectos estratégicos identificáveis que nele exercem pressão, com reflexos diretos em sua interface com o distribuidor, são a pressão da corporação por maior rentabilidade na linha de produtos de consumo da sua subsidiária, com o intuito de financiar outras divisões de produtos em fase de rápido crescimento; a dificuldade do fabricante em investir em aumento de produtividade, já que a corporação estava dando, à época do estudo, mais ênfase aos portfólios das suas outras divisões; e a desvantagem cambial.

A pressão que o fabricante tipicamente enfrenta por resultados de curto prazo, aliada à relativa inelasticidade preço-demanda na ponta do consumo, impede que os distribuidores da rede de suprimentos aumentem o seu giro aos níveis necessários, causando assim crises cíclicas no sistema quando seus membros não são capazes de absorver os excedentes fabricados. Essas crises são tipicamente efeito da instabilidade do modelo de cadeia "empurrada", que não alinha estrategicamente o interesse de todas as partes.

Acredita-se poder haver alguma resistência do nó "fabricante" à implantação de um sistema do tipo DMI, que lhe retira a capacidade de determinar as quantidades e o tempo das operações logísticas, atividades de sua responsabilidade no VMI tradicional. No entanto, a médio prazo, a migração da atividade de coordenação dos fluxos de informação e material para o distribuidor torna a cadeia "puxada", permitindo ao fabricante cuidar da sua competência central (HAMEL; PRAHALAD, 1994), ou seja, permite focar a redução de custos dos produtos e processos, e a diferenciação contínua exigida dos participantes do mercado de produtos de consumo não durável. A longo prazo, o repasse ao consumidor final de parte da redução de custo, obtida pela redução do impacto do efeito Forrester e do maior foco do fabricante na produção pode resultar em aumento da base de consumidores e, portanto, em aumento total de vendas. Portanto, o benefício do DMI para o fabricante, a médio prazo, seria a redução de custo dos produtos e, a longo prazo, o aumento das vendas por meio do alargamento da base de consumidores.
Considerações sobre os potenciais "novos entrantes" $e$ sobre os "concorrentes" do mercado: O aspecto "iniciantes" é também relevante no contexto de mercado analisado. Como o fabricante da cadeia analisada estava com a maioria dos produtos na fase de "maturidade" do ciclo vida, o reinvestimento na linha era muito limitado. Fazer pouco investimento significa diferenciar pouco, e, num mercado com baixas barreiras à entrada, isso implica a cessão progressiva de espaço para iniciantes. O principal risco vinha dos concorrentes que se posicionavam na estratégia de menor preço, pois a expansão no mercado brasileiro de produtos de consumo ocorria principalmente na base da pirâmide, seja pelo aumento do poder de consumo das classes de menor renda, ou pelo fenômeno de supressão da classe média, que realizava a substituição dos produtos de maior custo. Sob esse aspecto, o DMI novamente pode gerar valor para o distribuidor e para o fabricante, dificultando a entrada de novos concorrentes por meio da redução do custo total dos produtos.

Considerações sobre o poder de barganha dos clientes: $\mathrm{Na}$ interface com os varejistas, considera-se que o DMI pode representar elemento integrador e não de tensão entre as partes. Infelizmente, nenhuma pesquisa sobre essa relação foi localizada para o mercado nacional. Não obstante, Ortenzi (2000) realizou pesquisa no Reino Unido com a qual procurou identificar oportunidades de melhoria na cadeia de abastecimento do segmento de produtos de saúde. $\mathrm{Na}$ apresentação dos dados da pesquisa, a autora reporta o ranqueamento dos serviços mais importantes prestados pelos distribuidores de acordo com a percepção de farmácias, conforme se vê na Tabela 2.

Ortenzi (2000) também reportou as principais deficiências identificadas na operação dos distribuidores, conforme destacado na Tabela 3, com dados da mesma pesquisa.

Devido a semelhanças entre os mercados farmacêuticos do Reino Unido e do Brasil, evidenciadas pela pesquisa, decidiu-se pelo uso qualitativo daqueles dados como indicadores aproximados dos problemas e oportunidades do mercado local. Das dimensões avaliadas na pesquisa de Ortenzi (2000), quatro são diretamente afetadas, de forma positiva, pela proposta do DMI: informação sobre disponibilidade de estoques; freqüência de entrega; transparência nas condições comerciais; e apoio de sistema de TI nos negócios. Além disso, a maior deficiência indicada pela pesquisa foi a falta de informação sobre produtos e falta de produtos, cuja redução seria um dos principais objetivos do DMI.

Considerações sobre as "competências" envolvidas: Em termos de competências, dos três nós analisados da cadeia, 
o varejo tem o serviço ao consumidor e o fabricante tem o desenvolvimento de produtos e a produção como competências centrais naturais. A captação de dados, o envio de informações ao fabricante, a previsão de demanda, o controle e a reposição dos estoques do pequeno varejo surgiriam, então, em conjunto, como competências centrais do distribuidor.

A disseminação do sistema DMI pelos pontos-devenda poderia representar incremento na fidelidade ao distribuidor exclusivo e, por conseqüência, ao próprio fabricante, em decorrência dos serviços que complementariam o produto, em especial o gerenciamento do estoque com garantia de aumento de giro e segurança contra falta de produtos, o que elevaria a barreira de entrada a produtos substitutos via outra cadeia de distribuição. Adicionalmente, a organização peculiar de atividades da cadeia, que permite a geração de valor, remete ao conceito de ajustamento (fit) de Porter (1999), segundo o qual a estratégia de um negócio deve refletir primeiramente a combinação de um conjunto de atividades que atribua posição diferenciada à empresa e proporcione a ela uma vantagem competitiva sustentável.

Em síntese, o DMI apresenta indicações de que pode ser uma proposta de valor estratégico em várias interfaces do mercado com o distribuidor, e não apenas para este, mas potencialmente também para o fabricante e os varejistas da cadeia de abastecimento. Sua finalidade não seria apenas entregar os produtos necessários e suficientes no momento oportuno, mas também atribuir ao distribuidor a responsabilidade sobre a gestão de estoques do varejo e de informações de mercado ao fabricante, liberando recursos de ambos para cuidarem de suas competências centrais.

Tabela 2 - Ranking da importância dos serviços prestados pelo distribuidor, como percebida pelas farmácias do Reino Unido

\begin{tabular}{|l|c|}
\hline \multicolumn{1}{|c|}{ SERVIÇO } & IMPORTÂNCIA (DE 1 A 5) \\
\hline Informação sobre disponibilidade de estoques & 4,71 \\
\hline Entrega pontual & 4,67 \\
\hline Freqüência de entrega & 4,63 \\
\hline Rapidez de resposta do SAC & 4,57 \\
\hline Descontos competitivos & 4,47 \\
\hline Transparência nas condições comerciais & 4,06 \\
\hline Apoio de sistema de TI & 3,83 \\
\hline
\end{tabular}

Fonte: ORTENZI, 2000.

Tabela 3 - Oportunidades para melhoria de serviços por parte dos distribuidores

\begin{tabular}{|l|c|}
\hline \multicolumn{1}{|c|}{ DEFICIÊNCIA DO DISTRIBUIDOR } & PORCENTAGEM DAS FARMÁCIAS PESQUISADAS \\
& ONDE O PROBLEMA FOI DETECTADO \\
\hline Falta de informação sobre estoque/ quebra de estoque & $22,0 \%$ \\
\hline Baixos descontos para medicamentos genéricos. & $8,4 \%$ \\
\hline Desconhece os descontos & $2,0 \%$ \\
\hline Serviço ruim ao cliente & $2,0 \%$ \\
\hline Valor de pedidos mínimo & $1,3 \%$ \\
\hline Freqüência de fornecimento & $1,3 \%$ \\
\hline Dá mais atenção às cadeias de varejo de sua propriedade & $1,3 \%$ \\
\hline Entregas atrasadas & $1,3 \%$ \\
\hline Orientação para o lucro e não para o problema dos pacientes & $1,3 \%$ \\
\hline Não estabelecida na WEB & $1,3 \%$ \\
\hline
\end{tabular}

Fonte: ORTENZI, 2000. 


\section{Análise dinâmica}

Os resultados da análise dinâmica - segundo passo do critério de avaliação adotado - foram obtidos pela integração temporal do sistema de equações e condições de contorno ao longo de 50 semanas de simulação. Os comportamentos para o estoque do varejo, estoque do distribuidor e produção da fábrica, consideradas três das variáveis mais importantes para demonstração do valor dinâmico e econômico do modelo, foram reproduzidos nos gráficos das Figuras 3, 4 e 5 .

Figura 3 - Comportamento do estoque do varejo para o VMI e DMI proposto

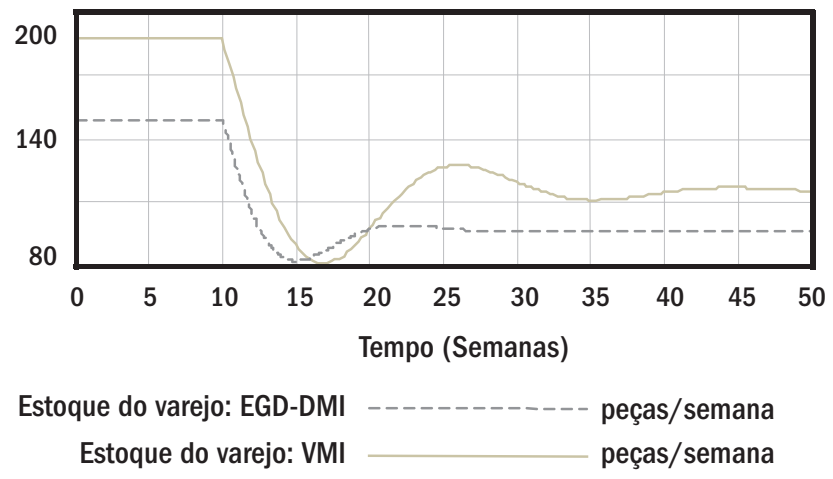

Figura 4 - Comportamento do estoque do distribuidor para o VMI e DMI proposto

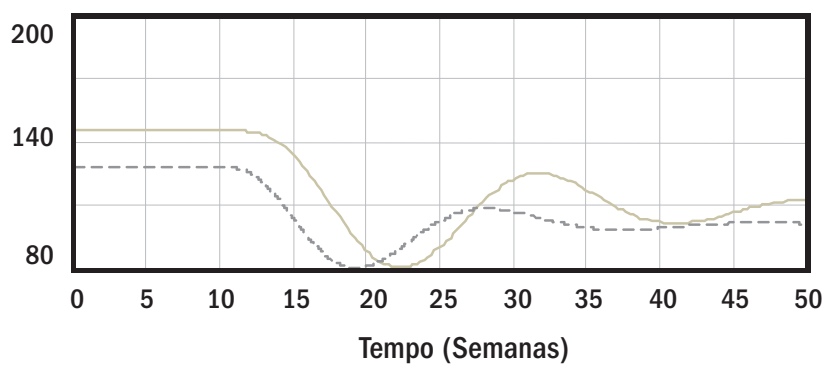

Estoque do distribuidor: EGD-DMI

peças/semana

Estoque do distribuidor: VMI

peças/semana

Figura 5 - Comportamento da produção da fábrica para o VMI e DMI proposto

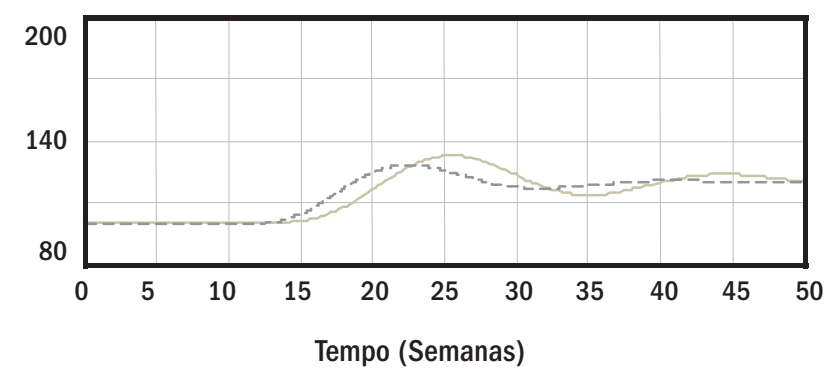

Produção da fábrica: EGD-DMI peças/semana

EProdução da fábrica: VMI peças/semana 
No caso do VMI, conforme Figura 3, quando sujeito a um acréscimo de demanda de $20 \%$ na semana 10 , o estoque inicial mínimo do varejo necessário para que não haja quebras é de 89 unidades. Como a operação no modelo DMI é mais estável, bastam 56 unidades de estoque antes do mesmo choque de demanda. Quando o sistema se estabiliza, por volta da 50a semana, os estoques são de 29 unidades no sistema VMI e de apenas 13 no DMI.

Para o distribuidor, a Figura 4 indica que o VMI exige um estoque inicial mínimo de 108 unidades para não haver falta com o aumento repentino de $20 \%$ na demanda. Já com o modelo DMI, bastam 89 unidades. Quando o sistema se estabiliza, também por volta da 50a semana, os estoques são de 54 unidades no sistema VMI e de apenas 36 no DMI.

A Figura 5 demonstra que o fabricante também desfruta das melhorias do sistema DMI: a produção na fábrica responde mais cedo à flutuação de demanda e alcança menores picos. A curva de produção tornase mais plana, o que representa menores custos de produção.

\section{Análise econômica}

Considerando-se a Margem Bruta típica de 20\% neste tipo de cadeia (SAAB, 2003) e subtraindo-se dela as Despesas Variáveis (impostos, frete e comissões sobre vendas), a Margem de Contribuição resultante para o distribuidor, na linha de produtos do fabricante em questão, era de $3,57 \%$ sobre o faturamento. Com esse resultado bruto, um distribuidor típico precisa custear as despesas fixas da sua organização, amortizar os investimentos realizados em infra-estrutura e gerar um retorno sobre o investimento acima do seu custo de oportunidade. Portanto, ao longo de um mês de operação, o produto Margem de Contribuição X Giro de Estoques tem que ser suficiente para custear as suas Despesas Fixas mais o Retorno sobre Ativos esperado.

Considerando que o distribuidor é parte de uma cadeia específica de abastecimento, e sob as premissas de que o relacionamento deveria ser equilibrado e de longo prazo, assumiu-se que o Retorno sobre Ativos deveria ser também semelhante para todos os nós da cadeia. Por isso, utilizou-se como valor para o ROA esperado pelo distribuidor o mesmo ROA médio do fabricante, calculado com base nos balanços públicos divulgados para sua linha de produtos de consumo no triênio 2000-2002, o que resultou em valor anual de $22,13 \%$.

Como o fabricante apresentava, à época da análise, sete cadeias de abastecimento de quatro níveis em todo o esta- do de São Paulo, e a escolha da Margem de Contribuição não apresentaria limitações para generalização da conclusão a qualquer uma delas, foi necessário estimar as diferentes necessidades de Giro de Estoques para os distribuidores envolvidos em todas essas cadeias, de forma a manter-se o potencial de generalização das conclusões para, ao menos, todo o Estado.

A análise indireta de alguns dados macroscópicos sobre os demais distribuidores do Estado, disponibilizados pelo fabricante, permitiu estimar que seus Custos Fixos eram da ordem de $7 \%$ a $11 \%$ de seus faturamentos. Ademais, seus ativos totais foram estimados entre 50\% e 200\% do faturamento mensal de cada um deles, em 2003. Com base nesses dados, foi realizado um estudo de sensibilidade (SAAB, 2003), que demonstrou a necessidade do giro situar-se no intervalo $[2,14$ e 3,80$]$ ao mês. Nesse mesmo período, a política de estocagem imposta pelo fabricante aos distribuidores estava na faixa de 40 dias de venda, resultando em giro de 0,75 ao mês, ou seja, de 3 a 5 vezes menor que o necessário.

A constatação de que na situação inicial havia desencontro entre a necessidade e a realidade do giro nos distribuidores dessa rede de suprimentos específica auxiliou a identificação e a compreensão de pelo menos um dos motivos pelos quais não havia alinhamento geral de objetivos na rede de suprimentos do fabricante; os distribuidores eram forçados a participar de pelo menos uma cadeia de abastecimento adicional, com cujos produtos pudessem obter Margem de Contribuição compensatória ou complementar, e o fabricante buscava implantar um sistema de informações para coordenar ele próprio a rede de suprimentos.

A análise econômica antes e após a implantação do modelo, terceiro e último passo da avaliação proposta, foi realizada por meio dos cálculos de estoque e giro para o distribuidor e o varejo, tendo por base os dados provenientes da análise dinâmica. Os dados obtidos foram sintetizados na Tabela 4.

\section{CONCLUSÕES}

O acompanhamento de um caso real de insucesso na tentativa de implantação do sistema VMI por três anos em uma cadeia de abastecimento de quatro níveis no setor de bens de consumo não duráveis indicou a possível inadequação do modelo VMI à cadeia de abastecimento analisada. Corroborando essa percepção, a pesquisa bibliográfica indicou a existência de registro de diversos outros casos de insucesso. A análise de aplicabilidade do modelo 
à cadeia demonstrou que o VMI subutiliza informações e não aborda suficientemente alguns aspectos conceituais e dinâmicos importantes, quando adaptado à cadeia de quatro níveis.

O processo de gestão alternativo proposto, o DMI, agregou a integração do ponto-de-venda (varejo) ao sistema de gestão e sua análise estratégica demonstrou que o distribuidor de uma cadeia específica poderia alcançar uma situação estratégica superior à de referência. Ao assumir a responsabilidade sobre o fluxo de informações e produtos acabados na cadeia de suprimentos, o distribuidor também permitiria aos seus parceiros focar em suas competências centrais.

A análise dinâmica da proposta demonstrou que o sistema comportou-se de forma (i) estável (convergente); (ii) amorteceu mais rapidamente as flutuações típicas da cadeia que apresentaram menor amplitude devido à maior velocidade do trânsito de informações; (iii) permitiu significativas reduções de estoque; e (iv) foi robusto a ponto de permitir à cadeia avaliada enfrentar um acréscimo de demanda instantâneo de $20 \%$, com estoques 55\% menores no varejo e 33\% menores no distribuidor, quando comparada à situação de referência (VMI).

A análise econômica, com base na simulação numérica e na necessidade específica da cadeia estudada, demonstrou que o sistema tem potencial para elevar o Giro Mensal do Distribuidor a até 13,3. Esse número é bastante superior ao intervalo mínimo necessário de $[2,14$ e 3,80] para os distribuidores do Estado de São Paulo da rede analisada alcançarem o ROA mínimo necessário com os negócios do fabricante, estimado em $22,13 \%$ a.a..

Como demonstrado pelo resultado da análise dinâmica (Figuras 3 a 5), seguido da análise econômica, o DMI apresentou vantagens para o varejo cujo giro alcançou o limite teórico de 36,9 giros ao mês, e também para o fabricante, pois a maior rapidez na identificação de flutuações de demanda permitiu uma resposta mais rápida do planejamento de produção e de compra de insumos.

O sistema DMI, simulado numericamente, integrou de tal forma o distribuidor ao varejista que se assemelhou a um encolhimento da cadeia, atendendo, para efeitos práticos, a recomendação original de Forrester (1973) para redução das flutuações na cadeia sem nenhum prejuízo à redução do custo de transação proporcionada pela presença do distribuidor na cadeia.

O resultado da análise pode ser estendido aos sete distribuidores do fabricante usado como caso para estudo, que atuam no Estado de São Paulo, com pouca ou nenhuma - adaptação, especialmente porque foram consideradas as faixas de despesas fixas e ativos que englobam todos eles nas estimativas de ROA e giros necessários.

Limitações mais sérias à generalização das conclusões são provenientes (i) dos modelos de relacionamento do fluxo de informação e de materiais usados para avaliar o desempenho do VMI e do DMI entre os entes da Cadeia de Abastecimento e (ii) da falta de uma pesquisa local sobre os problemas e oportunidades na interface distribuidorvarejo no mercado do Estado de São Paulo. Essas questões são apontadas como sugestões para prosseguimento desse trabalho.

Conforme demonstrado na bibliografia, cada cadeia é uma combinação particular e dificilmente reprodutível de muitas atividades, com distintos pontos de alavancagem dinâmica (SAAB; CORRÊA, 2005). Portanto, não se propõe a generalização automática dos resultados aqui apresentados para qualquer outra cadeia de abastecimento com particularidades de fluxo de informação e materiais diferentes do modelo proposto.

Os resultados permitem afirmar, no entanto, que sempre que uma cadeia de quatro níveis for candidata a ope-

Tabela 4 - Variação do estoque e giro num modelo de VMI que representa a cadeia específica estudada, e no modelo DMI proposto. Todas as comparações são feitas na qüinquagésima semana da simulação, portanto, com o sistema estabilizado

\begin{tabular}{|l|c|c|c|c|c|}
\hline & SISTEMA ATUAL & \multicolumn{2}{|c|}{ EGF-VMI } & \multicolumn{2}{c|}{ EGD-DMI } \\
\hline & DISTRIBUIDOR & VAREJ0 & DISTRIBUIDOR & VAREO & DISTRIBUIDOR \\
\hline Vendas (unid./sem.) & 120 & 120 & 120 & 120 & 120 \\
\hline Estoques (unidade) & 632 & 29 & 54 & 13 & 36 \\
\hline Giro (1/semana) & 0,19 & 4,1 & 2,2 & 9,2 & 3,3 \\
\hline Giro (1/mês) & 0,75 & 16,6 & 8,9 & 36,9 & 13,3 \\
\hline
\end{tabular}


rar sob o VMI, poderá atuar sob o DMI com potenciais vantagens, pois as diferenças entre os modelos não estão apenas no desempenho dinâmico e econômico, mas, principalmente, no próprio conceito de integração da cadeia de abastecimento. No DMI, a dinâmica se passa como se a cadeia de quatro níveis fosse reduzida a uma cadeia de três níveis, preservando-se, no entanto, a maior geração de valor da cadeia de quatro níveis e a qualidade da informação obtida no ponto-de-venda do varejo, minimizando assim as flutuações do sistema.

\section{REFERÊNCIAS}

ASSOCIAÇÃO BRASILEIRA DOS ATACADISTAS E DISTRIBUIDORES: Distribuição, 2003.

ALBERTIN, A. L. Comércio eletrônico. 3. ed. São Paulo: Atlas, 2001.

BAUMGARTEN, C. E. Os bandeirantes da era moderna. São Paulo: HB Editora, 2006.

BOWERSOX, D.; CLOSS, D. Logística empresarial: O processo de integração da cadeia de suprimentos. São Paulo: Atlas, 2001.

BROMWICH, M.; BHIMANI, A. Strategic investment appraisal. Management Accounting, v. 72, n. 9, p. 45-48, 1991.

COOKE, J. A. VMI: very mixed impact? Logistics Management and Distribution Report, v. 37, n. 12, p. 51-53, 1998.

CORRÊA, H. L. Teoria geral da administração: Abordagem histórica da gestão de produção e operações. São Paulo: Atlas, 2003.

CORRÊA, H. L.; Corrêa, C. A. Administração de produção e operações. 2. ed. São Paulo: Atlas, 2006.

CORRÊA, H. L.; Ellram, L.; Scavarda, A.; Cooper, M. An operations management view of the services and goods offering mix. International Journal of Operations and Production Management, v. 27, n. 5, p. 444$463,2007$.

FORRESTER, J. W. Industrial Dynamics. Cambridge, MA: MIT Press, 1973.

HAMEL, G.; PRAHALAD, C. K. Competing for the Future. Boston: Harvard Business School Press, 1994.

KOPCHENOVA, N. V.; MARON, I. A. Computational Mathematics: Worked Examples and Problems with Elements of Theory. Moscow: Mir, 1975
KAPLAN, R. S. Must CIM be justified by faith alone? Harvard Business Review, p. 87-95, Mar./Apr., 1986.

KIRKWOOD, C. W. System Dynamics Methods: A Quick Introduction Version 1- 4/1/1998.

LAMBIN, J. J. Market-Driven Management: Strategic \& Operational Marketing. London: Macmillan Business, 2000.

LEE, H. L.; PADMANABHAN, V.; WHANG, S. The bullwhip effect in supply chains. Sloan Management Review, p. 93-102, Spring 1997.

MINTZBERG, H.; AHLSTRAND, B.; LAMPEL, J . Strategy Safary: A Guide Tour through the Wilds of Strategic Management. New York: The Free Press, 1998.

ORTENZI, K. E. Reengineering the UK Pharmaceutical Supply Chain. 2000 118 p. Dissertação (Mestrado). Imperial College of Science, Technology and Medicine, London, 2000.

PARENTE, J. Varejo no Brasil. São Paulo: Atlas, 2000.

POIRIER, C. C.; REITER, S. E.: Otimizando sua rede de negócios. São Paulo: Futura, 1997.

PORTER, M. Competição: On Competition. Estratégias Competitivas Essenciais. 8. ed. São Paulo: Campus, 1999.

REIS, M. A. S. Logística. Escola de Administração de Empresas de São Paulo, Fundação Getulio Vargas, 2003 (Apostila).

ROSENBLOOM, B. Canais de marketing: Uma visão gerencial. Trad. da 6 ed. São Paulo: Atlas, 2002.

RYAN, M. Spartan pulls the plug on VMI. Progressive Grocer, v. 74, n. 11, p. 64, Nov., 1995.

SAAB, J. Y. Administração da cadeia de abastecimento: Considerações sobre a situação estratégica dos distribuidores paulistas de um fabricante multinacional de produtos de consumo da área de saúde e higiene pessoal e proposta do sistema de Estoque Gerido pelo Distribuidor (EGD/ DMI). Dissertação (Mestrado) - Escola de Administração de Empresas da Fundação Getulio Vargas, São Paulo, 2003.

SAAB, J. Y.; CORREAA, H. L. Bullwhip effect reduction in supply chain management: one size fits all? International Journal of Logistics Systems and Management, v. 1, n. 2/3, 2005.

SAMUELS, J. M.; WIKES, F. M.; BRAYSHAW, R. E. Management of Company Finance. 5. ed. London: Chapman and Hall, 1997.

SENGE, P. M. A quinta disciplina: arte e prática na organização que aprende. 11. ed. São Paulo: Best Seller, 2002.

SIMBARI, D. J. Competitive advantages. Manufacturing Systems, v. 14, n. 9, p. 92-96, Sept., 1996. 
SOUZA, R. F; Canais de marketing, valor e estrutura de governança. RAErevista de administração de empresas, v. 42, n. 2, p. 42-53, 2002.

STERMAN, J. D. Business dynamics: systems thinking and modeling for a complex world. New York: Irwin-McGraw-Hill, 2000.

VENSIM. Ventana Systems, Inc. Disponível em <http://www.vensim.com/>. Acesso em: 25 abr. 2003.
WALLER, M.; JOHNSON, M. E.; Davis, T. Vendor-managed inventory in the supply chain. Journal of Business Logistics, Oak Brooks, v. 20, n. 1, p. 183-203, 1999.

WALSH, C. Key Management Ratios. London: FT Pitman Publishing, 1996.

WILLIAMS, M. K. Making consignment- and vendor-managed inventory work for you. Hospital Material Management Quarterly. v. 21, n. 4, p. 5963, May 2000.

\section{Artigo recebido em 24.04.2006. Artigo aprovado em 10.10.2007.}

\section{Joseph Youssif Saab Junior}

Professor da Escola de Engenharia Mauá, Instituto Mauá de Tecnologia.

Mestre em Administração de Empresas pela FGV-EAESP.

E-mail: saab@maua.br

Endereço: Instituto Mauá de Tecnologia, Praça Mauá 1, São Caetano do Sul - São Paulo, 09580-900.

\section{Henrique Luiz Corrêa}

Professor da Crummer Graduate School of Business, Rollins College.

Doutor em Gestão de Operações pela University of Warwick Business School.

Interesses de pesquisa nas áreas de gestão estratégica de operações e gestão de redes globais de suprimento.

E-mail: hcorrea@rollins.edu

Endereço: Crummer Graduate School of Business, Rollins College, 1.000 Holt Avenue, Box 2722

Winter Park, Florida 32789-4499, USA 